\title{
Standing Seam Metal Roofing System Application in the Large-scale Public Buildings
}

\author{
Xuan GUO ${ }^{1, a,{ }^{*},}$, Xiao-Xin ZHANG ${ }^{2, b}$
}

${ }^{1}$ School of civil engineering, Beijing Jiaotong University,No.3 ShangYuan Cun, Haidian District Beijing,China, 100044

${ }^{2}$ China construction engineering design Group Corporation limited, No.15 Sanlihe Road, Haidian District, Beijing, China, 100037

axguo@bjtu.edu.cn, bfx2002@163.com

${ }^{*}$ Corresponding author

Keywords: Complicated Roofing System, Point-braced, Over-length Sheet, Integrality, Flexibility.

\begin{abstract}
System introduced standing seam roofing system, which is mainly used in large-span self-supporting structure of a closed system; in recent years, with the further development of metal materials technology and engineering technology, since the metal roofing system with light weight, durability and high economic performance, strong adaptability appearance (appearance can meet the needs of different types of buildings), with thermal insulation, sound-absorbing barrier sound, waterproof, green features, many domestic large-scale public construction projects (especially the roof with a certain architectural style requirements of the project) roof parts are made of metal roofing systems.
\end{abstract}

\section{Introduction}

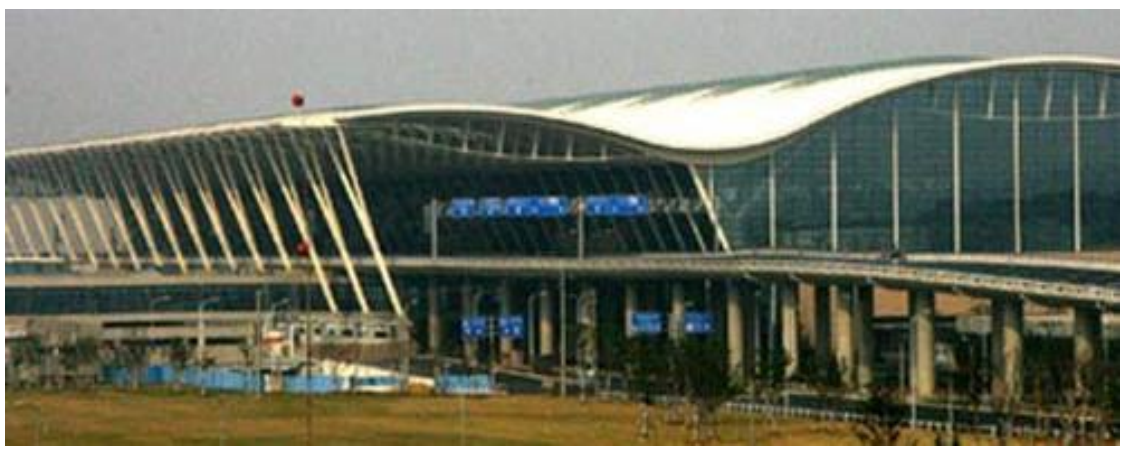

(a) Pudong Airport T2 Terminal Building (2008)

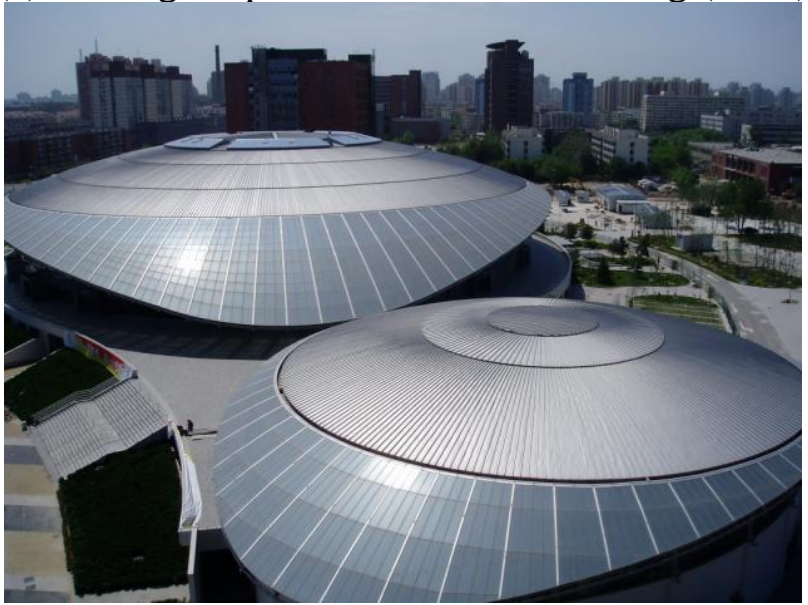

(b) Beijing University of Technology Gymnasium (2008)

Fig.1 Standing Seam Metal Roofing System in Large-scale Public Buildings 
Application of China's modern standing seam metal roofing system ${ }^{[1]}$ started late, the application of standing seam metal roof is starting from the industrial buildings, before and after the 80s of last century, Shanghai Baosteel engineering began to application to raise awareness of standing seam metal roofing systems used in the construction of roof superiority. Since then, the light steel structure and large span structures in Chinese application development more and more, also promote the standing seam metal roof system has been widely used.

Standing seam metal roofing system in large-scale public buildings is widely used, such as the Pudong airport T3 terminal building (Shanghai, 2008), Beijing University of Technology Gymnasium (Beijing, 2008), as shown in Fig.1.

\section{Aluminum Alloys Roofing System}

This system does not need for the control thermal distortion and the resistance wind load to punch on the sheet for clamping screw, moreover no matter how the building shape, the aluminum alloy roofing sheet always can crimps the standing seams well. Thus, this system's weight is light and its integrity is well with the high bear ability and stability, the rainproof performance is also fine. This kind of system typical constructing as Fig.2 shows. Because the sheet crosses section has the short rib, which also can guarantee the sheet in certain degree lateral deformation, at the same time strengthened the sheet rigidity.

The roofing system main characteristic includes:

1) The aluminum alloy sheet can be prefabricated in the factory, but when the extra long sheet must be used in the project while the ground is permitted the aluminum alloy sheet should be processed in construction site.

2) The aluminum alloy sheet is fastened by clips with thermal barrier pads, the fixed clips uses the thermal barrier pads is for avoiding appear the phenomenon of dew, the fastening of the profiled aluminium sheets is accomplished by means of special clips embedded in the beads without penetrating the roof skin. This result in a rain proofed roof and in addition to that allows the free thermal elongation of the profiled sheets. And because the sheet crosses section has the short rib, which also can guarantee the sheet in certain degree lateral deformation, at the same time strengthened the sheet rigidity.

3) The material of both roofing sheet and the clips are aluminum alloy, and in the most of weathers, the aluminum alloy has the ability of corrosion-resistance.

4) This system has the mature measure to open the hole on the roof and against lightning, aluminum alloy roofing sheet thickness generally $\geq 0.9 \mathrm{~mm}$, according to the 'Design code for protection of structures against lightning ${ }^{[2]}$, the sheet can acts as a lightning arrester and does not use the extra establishment lightning protection system, this item have already the project practice.

5) There are also have fan-shaped sheets, therefore may satisfy and develop the multiplicity and the complexity of projects.

\section{Common Technical Data}

Common aluminum alloy roofing system mechanics performance as follows:

Aluminum alloy roofing systems bear capacity (take $0.9 \mathrm{~mm}$ thickness sheet as example, Table 1).

Aluminum alloy sheet smooth curved in factory technology data (Table 2).

Aluminum alloy sheet smooth curved by itself technology data (Table 3). 
Tab.1 Aluminum Alloy Roofing Systems Bear Capacity

\begin{tabular}{|c|c|c|c|c|}
\hline \multirow{2}{*}{ Load Condition } & \multicolumn{4}{|c|}{ Bearing Capacity $\left(\mathrm{KN} / \mathrm{m}^{2}\right)$} \\
\cline { 2 - 5 } & Span $1.5 \mathrm{~m}$ & Span $2.0 \mathrm{~m}$ & Span $2.5 \mathrm{~m}$ & Span $3.0 \mathrm{~m}$ \\
\hline Load of Snow & 2.50 & 2.50 & 1.45 & 0.75 \\
\hline Suction of Wind & 4.60 & 2.85 & 1.95 & 1.40 \\
\hline
\end{tabular}

Tab.2 Aluminum Alloy Sheet Smooth Curved Radius in Factory

\begin{tabular}{|c|c|c|c|c|c|c|c|c|c|}
\hline Curve & $\begin{array}{c}\text { Sheet } \\
\text { thickness }\end{array}$ & \multicolumn{2}{|c|}{$0.8 \mathrm{~mm}$} & \multicolumn{2}{c|}{$0.9 \mathrm{~mm}$} & \multicolumn{2}{c|}{$1.0 \mathrm{~mm}$} & \multicolumn{2}{c|}{$1.2 \mathrm{~mm}$} \\
\hline & Type & Stan. & Limit & Stan. & Limit & Stan. & Limit & Stan. & Limit \\
\hline $\begin{array}{c}\text { Convex } \\
\text { ○ }\end{array}$ & $65 / 305$ & 12 & 7 & 6 & 4.5 & 3.5 & 2.2 & 2.5 & 1.5 \\
\hline $\begin{array}{c}\text { Concave } \\
\text { C }\end{array}$ & $65 / 305$ & - & - & 25 & 18 & 18 & 12 & 20 & 16 \\
\hline
\end{tabular}

Standard: Constant radius over the whole sheet length.

Limit: Tolerance limits.

Length of profiled sheet: Minimum length $1.5 \mathrm{~m}$.

Tab.3 Aluminum Alloy Sheet Smooth Curved by Itself

\begin{tabular}{|c|c|c|c|c|}
\hline Type & $\begin{array}{c}\text { Sheet thickness } \\
(\mathrm{mm})\end{array}$ & $\begin{array}{c}\text { Suggested clips } \\
\text { spacing }(\mathrm{m})\end{array}$ & $\begin{array}{c}\text { Convex } \\
\mathrm{Ri}(\mathrm{m})\end{array}$ & $\begin{array}{c}\text { Concave \.) } \\
\mathrm{Ri}(\mathrm{m})\end{array}$ \\
\hline \multirow{3}{*}{$65 /$} & 0.8 & 1.50 & 36.0 & 40.0 \\
\cline { 2 - 5 } 305 & 0.9 & 1.60 & 40.0 & 45.0 \\
\cline { 2 - 5 } & 1.0 & 1.80 & 45.0 & 50.0 \\
\cline { 2 - 5 } & 1.2 & 2.00 & 52.0 & 60.0 \\
\hline
\end{tabular}

\section{Physical Performances}

Heat-insulation coefficients of common heat preservation material of Aluminium alloy roofing system.The commonly used $100 \mathrm{~mm}$ thick rock wool average heat exchange coefficient is $0.033 \mathrm{~W} /$ (m. K)

Sound absorption capability of Aluminium alloy roofing system

Reverberation time $1.7 \sim 2.0 \mathrm{~S}, 2,000 \sim 4000 \mathrm{~Hz}$ absorption coefficient average value is $0.92 \sim 0.98$.

\section{Project Examples}

This part mainly put forward the details should be paid attention to especially in designing and practicing from design and construction project practices that author had participated in.

These buildings after many years of service, direct proof of the excellent overall performance of standing seam metal roof system.

\section{Shenyang Taoxian International Airport Terminals}

This building (Fig.4) is composed by two-piece of concave curve roof, which looks like a Chinese character "ren", and the structure is girder construction. 


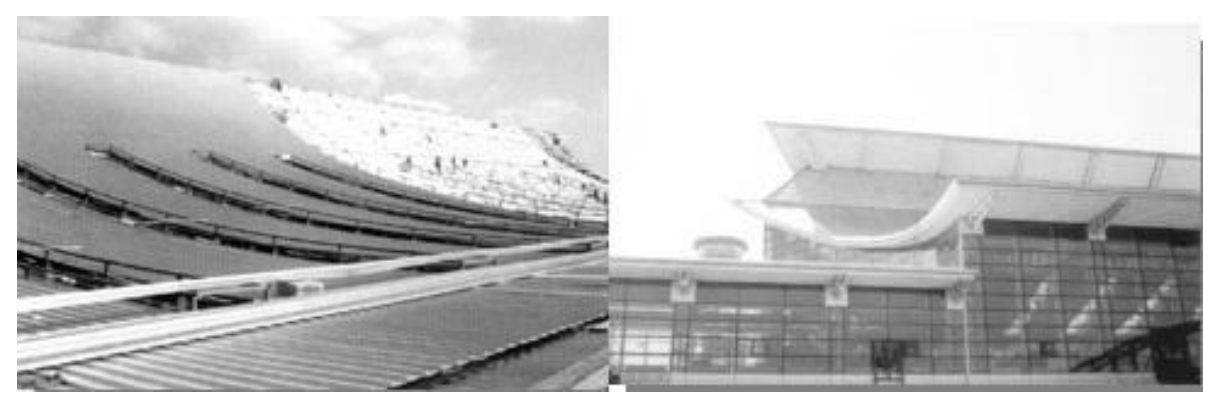

Fig.2 Shenyang Taoxian International Airport Terminals Outward Appearance

Author had participated in the design and construction of this project, the characteristic of this project is: The two-piece of roofs are all concave curve roof, moreover because two roofs are installed the belt shape louver (breadth of the middle is large than the end), therefore the spacing of clips along the sheet width direction may be appropriate readjusted, generally speaking, narrow in wave crest, width in the end. The roof against lightning measure is uses the lightning rod, the position at the roof middle peak.

\section{The People's Great Hall of Zhejiang Province}

The people's great hall of Zhejiang province is composed by three picturesque disorder constructions; three groups of buildings' roofs are all the convex curved roofs, the roofs are installed the constant width belt shape louver. A small roof on the main construction, which likes a hump, the curvature change of this part roof is bigger. Author had participated in the design and construction of this project. And a reference report is by Zhang jian er and Wang hong ${ }^{[3]}$.

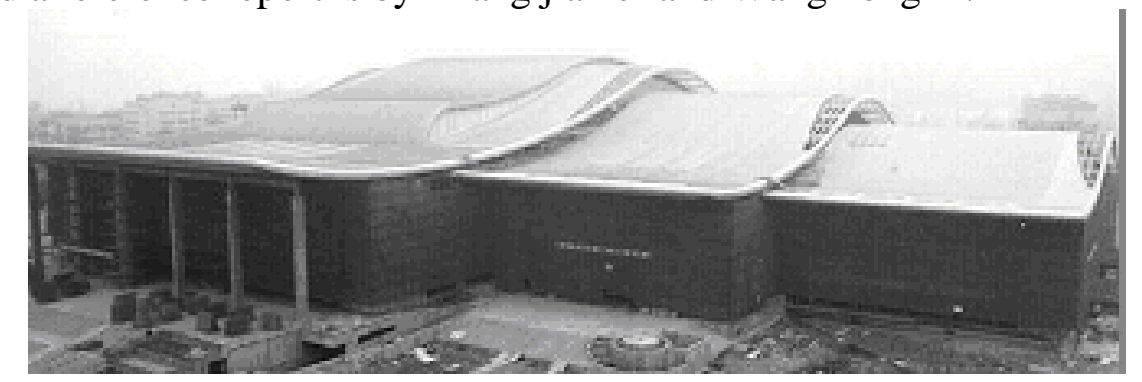

Fig.3 The People's Great Hall of Zhejiang Province Outward Appearance

Because one end (this end separated with the upside roof in the place curvature change) of the 'hump' roof's radius of curvature is small excessively $(12 \mathrm{~m})$, and aluminum alloy sheet smooth curved by itself is unable to achieve the such small radius, therefore this part of sheet must carried on preprocessing by machinery. Because of the good elasticity and the flexibility of aluminum alloy cause this part of sheets keep the curve continuous and smooth after the sheets were preprocessed and mechanical seamed. If when the curved radius is smaller than that the smooth curved sheets can achieve, the sheets also may be bended at the knees to a smaller radius, but this is at the cost of destroyed the integrity, continuity and smoothness of the roof.

For this system, expand with heat and contract with cold is the most important question that it should be solved, and this is also very important to the gutter, therefore the gutter should as far as possible adopt the measure that separated with the structure to guarantee it can move freely. If it adopt the way that fixed with the structure, then the gutter would be rip easily at welding line, therefore it must be installed structure expansion joint at the spacing $\leqslant 25 \mathrm{~m}$, but the practice proved that this kind of processing measure effect would not be ideal, so this measure is not recommend.

Considering the artistic appearance of this building, so it is not adopted the extra lightning protection measure, but uses the sheet acts as a lightning arrester according to the 'Design code for protection of structures against lightning. Because of sheet and fixed clips contacts well, and the fixed clips is also connected well with the structure through the self-tapping screw, after spot actual measure, from the sheet to the base of steel structure the resistance $\leqslant 3 \Omega$, satisfies the Code request 
completely. But considering the importance of the building, some strengthens measures have adopted which as follows:1) The arc aluminum strips (specification: $50 \times 1 \mathrm{~mm}$ ) are welded at the $6 \mathrm{~m}$ spacing between the outside of gutter and the sheet of its upside eaves while use the aluminum strips (specification here:50 $\times 2.5 \mathrm{~mm}$ ) are welded with the inside of gutter in one end and the other end are connected with steel strip which extracted from structure, and aluminum strips are also connected with the sheet of other eaves and steel structure as the same way. 2) When the aluminum strips connected with the steel strips (the same specification with aluminum strips) that are welded with the downside steel structure in one end, considering the reaction of electrochemistry between aluminum and steel, the following processing measures are taken: The tin-plating copper sheet is laid or electric conduction ester is packed between two kinds of tinsels, and fixed by bolts.

\section{National Great Theater}

The roof appearance of National great theater is hyperbolic which looks like an egg, so theirs characteristic also is their's difficulty in construction. Generally speaking there have two solutions at present regarding the hyperbolic fan-shaped roof: 1) The roof may be divided several parts, so the normal width sheet can be used, and the advantage of this method is that the construction fast, the joint is easy to process; the shortcoming is the roof cannot maintain continuously the smooth curve. The representative project practice that uses this method is Tianjin sports center gymnasium where the 43rd World Table Tennis Championship had been hold successfully. 2) Fan-shaped sheets can be used, the advantage is the roof can maintain the smooth curve, the shortcoming is the length of fan-shaped sheets is restricted $(\leq 12 \mathrm{~m})$, when dimensions of roof are excessively long, the first measure must be adopted, and when the hyperbolic curvature of the roof excessively large (for example the radius of spherical shell roof is small), similarly measures are adopted. The part of roofing system of National great theater had been adopted this measure, as well as Huanglong gymnasium project [3]. (This three projects were designed and constructed by my colleague)

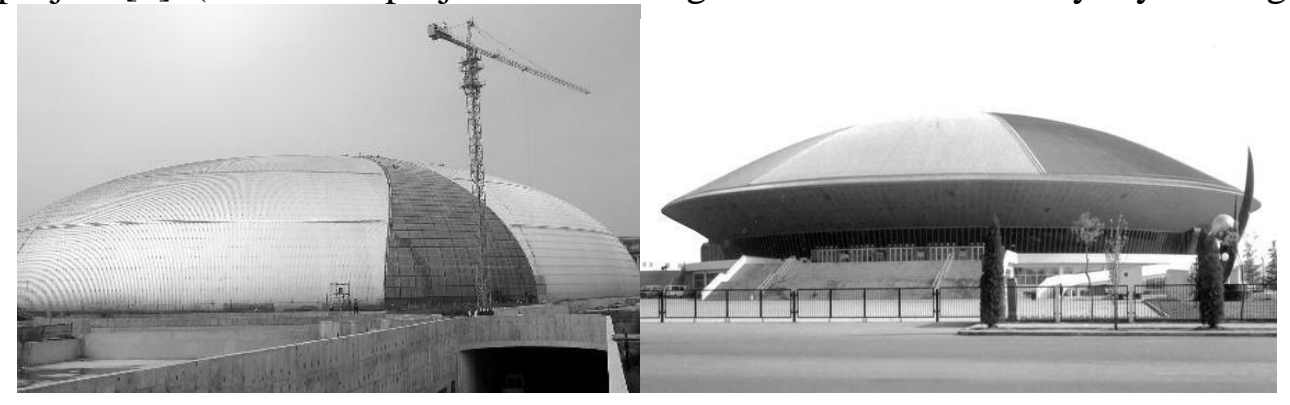

Fig.4 National Great Theater (Left) and Tianjin Sports Center (Right) Gymnasium

\section{Summary}

Standing seam metal roof system was indicated of useful favorable into the complicated large span roof shape such as bulgy arc, concave arc and hyperboloid etc[4-5]. The property of particular over-length sheet and the point-braced system, which can guarantee the smooth slide of metal sheet, is superior to the congener system of colored steel sheet. This new system not only can meet the functional need of the building and demand for using but also can be installed faster and more convenient, so it can reduce the cost of construction. The flexibility and superiority of design and practice of this new system was proved.

The use of standing seam metal roofing system and need to comprehensive consideration of the influence condition of building, such as local climate, environmental conditions, priority should be given to the applicability of the roofing system, then consider beautiful appearance of buildings, because once the installation is difficult to repair metal roofing system details choose undeserved tends to produce a lot of problems ${ }^{[4-5]}$. 


\section{Acknowledgement}

Supported by the National Natural Science Foundation of China (Grant No. 51378051), Fok Ying Tung Education Foundation (Grant No. 122009) and Fundamental Research Funds for the Central Universities of Beijing Jiaotong University (Grant No. 2011JBZ008).

\section{References}

[1]. Load Code for the design of building structures (GB 50009-2012), (2012).

[2]. Design code for protection of Structures against lightning (GB 50057-2010), (2010).

[3]. Zhang jian er and Wang hong. (2002). The construction of bemo roofing system of the people's great hall of Zhejiang province. Zhejiang Construction. 117:6, 28-29.

[4]. Zeng jian and Song gao sheng. (2004). Al-Mn-Mg alloyed sheet used on huanglong gymnasium roofing. Architecture Technology. 35:7, 494-496.

[5]. Daniel J. Smith, Forrest J. Masters, Arindam G. Chowdhury,Investigating a wind tunnel method for determining wind-induced loads on roofing tiles,2016,155(8):47-59. 